\title{
PENERAPAN METODE LINIER PROGRAMMING UNTUK MEMBUAT PERENCANAAN PRODUKSI YANG OPTIMAL
}

\author{
Ayudina Puji E , Bagus Asmono $^{2}$
}

\begin{abstract}
Alocation problem of sources among the chalbanged activities will appear when company have to some activities that have limited resources to do it like PT.Berlina Plastics Pandaan face limited time machine for their each activity makes under time and over time on it. This make unexpected production cost caused subjective production planning that have been done based on the last experience.

To solve this problem we can use linier programming to find optimum production planning to look for the best fisible alternative aims. Firstly, forecast the next demand using moving average method, single exponential smoothing method, double exponential smoothing and winter's method. Then find the lowest MAPE (Mean Apsolute Prosentage Error) after that use linier programming with QS program as a good to find optimum goal that have low overtime and reguler time can be used efectivelly without undertime with overall production cost about Rp 2.144.802.688,00 aalong next six months.
\end{abstract}

Key Words : Schedulling, linier programming, optimum

\section{PENDAHULUAN}

\section{Pada P.T. Berlina Plastics}

Pandaan merupakan perusahaan job-order yang bergerak dalam bidang pembuat kemasan dari plastic, diantaranya Botol Citra $60 \mathrm{ml}$ wl bengkoang, Botol Citra 120 $\mathrm{ml}$, Botol Lux $100 \mathrm{ml}$, Botol Lux $300 \mathrm{ml}$, Kendala yang dihadapi perusahaan ini adalah sering kali terjadi pembengkakan total biaya produksi yang diakibatkan oleh timbulnya biaya over time, under time, dan juga inventori yang terlalu berlebihan, sehingga menyebabkan keuntungan yang tidak bisa maksimal. Hal ini terjadi akibat dari perusahaan Berlina Plastics masih dihadapkan pada keterbatasan kapasitas jam operasi mesin. Maka diperlukan metode Linier Programming yang bisa menyelesaikan minimasi biaya produksi.

\section{TINJAUAN PUSTAKA}

\section{Linier Programming}

Menurut Tjutju Tarliah Dimyati,-Ahmad Dimyati, (1992, h.38), Pada dasarnya metode-metode yang dikembangkan untuk memecahkan model Programa Linier ditujukan untuk mencari solusi dari beberapa alternatif solusi yang dibentuk oleh persamaan-persamaan pembatassehingga diperoleh nilai fungsi tujuan yang optimum.

\section{Menurut $\quad$ T. Hani}

Handoko, (1984, h. 379), Linier Programming adalah suatu metode analitik paling terkenal yang merupakan suatu bagian kelompok teknik-teknik yang disebut programasi matematik. Pada umumnya, metoda-metoda programasi matematikal 
dirancang untuk mengalokasikan berbagai sumber daya yang terbatas diantara berbagai alternatif penggunaan sumber daya -sumber daya tersebut agar berbagai tujuan yang telah ditetapkan, yaitu maksimasi laba atau minimasi biaya yang dicapai atau dioptimalkan.

\section{Sebutan " Linier " dalam Linier} Programming berarti hubungan-hubungan antara factor-faktor adalah bersifat linier atau konstan,atau fungsi-fungsi matematik yang disajikan dalam model haruslah fungsifungsi linier. Hubungan-hubungan Linier berarti bahwa bila suatu faktor berubah maka suatu faktor lain berubah dan ddengan jumlah yang konstan secara proporsional. Sebagai contoh, fungsi pengupahan jam kerja para karyawan atas dasar satuan jam kerja adalah linier : semakin banyak jam kerja, semakin besar upah total. Linieritas dapat juga berarti sebaliknya ; semakin bertambahnya sesuatu, semakin berkurangnya sesuatu yang lain.

\section{Model Linier Programming}

Masalah Linier Programming dapat dinyatakan sebagai proses optimasi suatu fungsi tujuan ( objective function ) dalam bentuk :

Maksimumkan ( minimumkan ) $\mathrm{Z}=\mathrm{C}_{1} \mathrm{X}_{1}+$ $\mathrm{C}_{2} \mathrm{X}_{2}+\ldots \ldots+\mathrm{C}_{\mathrm{n}} \mathrm{X}_{\mathrm{n}}$

Dengan mengingat batasan-batasan sumber daya dalam bentuk :

$$
\begin{aligned}
& A_{11} X_{1}+A_{12} X_{2}+\ldots \ldots+A_{1 n} X_{n} \leq B_{1} \\
& A_{21} X_{1}+A_{22} X_{2}+\ldots \ldots+A_{2 n} X_{n} \leq B_{2} \\
& A_{m 1} X_{1}+A_{m 2} X_{2}+\ldots \ldots+A_{m n} X_{n} \leq B_{m}
\end{aligned}
$$

Dan

$$
\mathrm{X}_{1} \geq 0, \mathrm{X}_{2} \geq 0 \ldots \ldots \ldots . \mathrm{X}_{\mathrm{n}} \geq 0
$$

(Sumber : T. Hani Handoko, 1984,

Dimana $\mathrm{Cj}$, Aij dan $\mathrm{Bi}$ adalah masukan masukan konstan yang sering disebut sebagai parameter model.

Formulasi diatas dinamakan sebagai bentuk standart dari persoalan Linier Programming, dan setiap situasi yang formulasi matematisnya memenuhi model ini adalah persoalan Programa Linier. Istilah yang lebih umum dari model programa Linier ini adalah sebagai berikut :

a. Fungsi yang dimaksimumkan, yaitu $c_{1} x_{1}+c_{2} x_{2}+\ldots . .+c_{n} x_{n}$, disebut sebagai fungsi tujuan.

b. Pembatas-pembatas atau konstrain

c. Sebanyak $m$ buah konstrain pertama sering disebut sebagai konstrain fungsional atau pembatas teknologis.

d. Pembatas $x_{j} \geq 0$ disebut sebagai konstrain non negatif.

e. Variabel $\mathrm{x}_{\mathrm{j}}$ adalah variabel keputusan.

f. Konstanta-konstanta $a_{i j}, b_{i}$ dan $\mathrm{c}_{\mathrm{j}}$ adalah parameter-parameter model

(Sumber : Tjutju Tarliah Dimyati-Ahmad Dimyati, 1992, h. 25$)$

Agar Linier Programming dapat diterapkan, asumsi-asumsi dasar berikut ini harus ditepati :

1. Fungsi Tujuan dan Persamaan setiap batasan harus linier, ini mencakup pengertian bahwa perubahan nilai $\mathrm{Z}$ 
dan penggunaan sumber daya terjadi secara proporsional dengan perubahan tingkat kegiatan ( proportionality ).

Maksimum $\mathrm{Z}=\mathrm{C}_{1} \mathrm{X}_{1}+\mathrm{C}_{2} \mathrm{X}_{2}+\mathrm{C}_{3} \mathrm{X}_{3}$ $+\ldots . .+C_{n} X_{j}$

Atau

Minimum $Z=C_{1} X_{1}+C_{2} X_{2}+C_{3} X_{3}$ $+\ldots . .+C_{n} X_{j}$

2. Parameter-parameter harus diketahui atau dapat diperkirakan dengan pasti ( diterministic ). Dengan kata lain, probabilitas terjadinya setiap nilai $\mathbf{C} \mathbf{j}$, Aij dan Bi dianggap 1,0.

3. Variabel-variabel keputusan harus dapat dibagi ; ini berarti bahwa suatu penyelesaian" feasible " dapat berupa bilangan pecahan, misal : $\frac{1}{2} \quad X_{1}$ atau $\frac{1}{4} X_{2}$, dan sebagainya.

\section{METODOLOGI PENELITIAN}

\section{Metode secara Operasional}

Metode operasional

mendapatkan data perusahaan secara tepat dan cepat adalah dengan menggunakan metode pengamatan langsung (Field Research). Yaitu metode penelitian yang dilakukan ditempat penelitian dilaksanakan, dalam hal ini digunakan dua teknik pengumpulan data diantaranya :

1. Teknik Observasi

2. Teknik Interview

\section{Metodologi Pemecahan Masalah}

Metodologi penelitian yang digunakan dalam penulisan skripsi ini adalah sebagai berikut :

1. Riset Lapangan
a. Data wawancara.
b. Data kuesioner.
c. Data observasi.

2. Riset Kepustakaan.

$$
\text { Penelitian kepustakaan }
$$

dilakukan untuk mendukung riset lapangan yang dilakukan. Riset ini dilakukan dengan cara membaca buku-buku yang berkaitan dengan topik dan masalah yang dihadapi untuk memecahkan masalah dalam penelitian tersebut.

\section{Data yang Diperlukan}

Adapun data yang diperlukan untuk analisa antara lain :

\section{Data Permintaan}

Tabel 1

Data Historis Permintaan

\begin{tabular}{|c|l|c|c|c|c|}
\hline No & \multicolumn{1}{|c|}{ Periode } & \multicolumn{4}{|c|}{ Produksi } \\
\cline { 3 - 6 } & & $\begin{array}{c}\text { CT 60 } \\
\text { ml }\end{array}$ & $\begin{array}{c}\text { CT 120 } \\
\text { ml }\end{array}$ & $\begin{array}{c}\text { L-BS 100 } \\
\text { ml }\end{array}$ & $\begin{array}{c}\text { L-BS300 } \\
\text { mI }\end{array}$ \\
\hline 1 & Juli 2001 & 358290 & 242500 & 321000 & 270900 \\
\hline 2 & Agustus 2001 & 370650 & 247500 & 328860 & 282725 \\
\hline 3 & September2001 & 444780 & 255000 & 357550 & 295625 \\
\hline 4 & Oktober 2001 & 451840 & 186000 & 349750 & 319275 \\
\hline
\end{tabular}




\begin{tabular}{|c|l|c|c|c|c|}
\hline 5 & November 2001 & 455370 & 194000 & 339500 & 311750 \\
\hline 6 & Desember 2001 & 444780 & 197000 & 328860 & 292400 \\
\hline 7 & Januari 2002 & 469490 & 208000 & 378450 & 317000 \\
\hline 8 & Februari 2002 & 453600 & 216000 & 417600 & 318200 \\
\hline 9 & Maret 2002 & 451840 & 208000 & 370650 & 332150 \\
\hline 10 & April 2002 & 467725 & 232000 & 417600 & 352600 \\
\hline 11 & Mei 2002 & 483600 & 204000 & 388890 & 35450 \\
\hline 12 & Juni 2002 & 455370 & 239000 & 407460 & 348300 \\
\hline
\end{tabular}

\section{Jenis Produk}

Berbagai macam jenis produk yang diproduksi pada PT. Berlina Plastics Pandaan pada departemen pembotolan terdiri atas 4 jenis produk yang merupakan jenis produk yang telah mempunyai permintaan dan memiliki aliran produksi yang sama ditunjukkan pada tabel 4.1.

\section{Tabel 2}

\section{Data Jenis Produk}

\begin{tabular}{|l|l|l|l|}
\hline No & \multicolumn{1}{|c|}{$\begin{array}{c}\text { Grup } \\
\text { Produk }\end{array}$} & $\begin{array}{c}\text { Jenis } \\
\text { Produk }\end{array}$ & \multicolumn{1}{|c|}{$\begin{array}{c}\text { Kode } \\
\text { Produk }\end{array}$} \\
\hline 1 & Botol Citra & Citra $60 \mathrm{ml}$ & CT $60 \mathrm{ml}$ \\
\hline 2 & Botol Citra & Citra $120 \mathrm{ml}$ & CT $120 \mathrm{ml}$ \\
\hline 3 & Botol Lux & Lux $100 \mathrm{ml}$ & L-BS $100 \mathrm{ml}$ \\
\hline 4 & Botol Lux & Lux $300 \mathrm{ml}$ & L-BS $300 \mathrm{ml}$ \\
\hline
\end{tabular}

Sumber : P.T. Berlina Plastics (Juni

2002)

\section{Mesin dan Peralatan}

Pada departemen pembotolan di P.T. Berlina Plastics memiliki beberapa mesin dan peralatan untuk produksi yang dipakai untuk membuat keempat jenis botol adalah mesin blow molding, yang terdiri atas 2 jenis mesin, mesin injeksi, mesin printing dan crocking tower. Data jenis dan jumlah mesin-mesin tersebut seperti pada tabel 2 .
Tabel 3

Data Mesin dan Peralatan

\begin{tabular}{|c|l|c|}
\hline No & \multicolumn{1}{|c|}{ Mesin dan Peralatan } & $\begin{array}{c}\text { Jumlah } \\
\text { (unit) }\end{array}$ \\
\hline 1 & Blow Moulding Lien Yu Tipe HLL & 3 \\
\hline 2 & Blow Moulding Lien Yu Tipe HGL & 1 \\
\hline 3 & Injection Moulding Nissei & 4 \\
\hline 4 & Mesin Printing & 4 \\
\hline 5 & Crocking Tower & 8 \\
\hline
\end{tabular}

Sumber :P.T. Berlina Plastics (Juni 2002)

\section{Waktu Produksi}

Dalam perhitungan perencanaan Produksi harus diketahui waktu pembuatan satu unit produk. Pendekatan yang dapat dilakukan adalah mengkonversikan satu unit produk kedalam waktu produksinya. Sedangkan kapasitas alternatif produksi dinyatakan dalam satuan waktu.

Data waktu produksi diperoleh dari bagian produksi P.T. Berlina PlasticsPandaan, seperti yang terlihat pada peta proses operasi disebutkan waktu baku untuk 30 unit. Berarti dalam satu waktu proses didapatkan keluaran produk 30 unit.Data tersebut merupakan data waktu baku tiap aktifitas produksi yang ada dengan satuan waktu dalam jam. Data waktu produksi masing-masing jenis produk dapat dilihat pada tabel dibawah ini : 
Waktu Produksi $=$

Jam reguler tersedia

Kapasitas produk per hari

$$
=\frac{16(\text { jam })}{17000(\text { unit })}
$$

$$
=0.00094 \mathrm{jam}
$$

Untuk mengetahui waktu standart tiap-tiap jenis produk dilakukan dengan perhitungan yang sama, data selengkapnya dapat dilihatpada tabel

4.

\section{Tabel 4}

Data Waktu Produksi Tiap Produk

\begin{tabular}{|c|c|c|c|c|}
\hline No & $\begin{array}{c}\text { Grup } \\
\text { Produk }\end{array}$ & $\begin{array}{c}\text { Jenis } \\
\text { Produk }\end{array}$ & $\begin{array}{c}\text { Kode } \\
\text { Produk }\end{array}$ & $\begin{array}{c}\text { Waktu Produksi } \\
\text { (jam) }\end{array}$ \\
\hline 1 & Botol Citra & Citra $60 \mathrm{ml}$ & CT $60 \mathrm{ml}$ & 0.00094 \\
\hline 2 & Botol Citra & Citra $120 \mathrm{ml}$ & CT $120 \mathrm{ml}$ & 0.00107 \\
\hline 3 & Botol Lux & Lux $100 \mathrm{ml}$ & L-BS $100 \mathrm{ml}$ & 0.001 \\
\hline 4 & Botol Lux & Lux $300 \mathrm{ml}$ & L-BS 300ml & 0.00123 \\
\hline
\end{tabular}

Sumber : P.T. Berlina Plastics (Juni 2002)

\section{Prosentase Cacat Produk}

Botol yang diproduksi pada departemen pembotolan tidak semuanya sesuai dengan standart perusahaan, dan prosentase cacat tersebut dapat diketahui setelah dilakukan beberapa macam percobaan pengambilan sampel, pihak manajemen di departemen pembotolan menetapkan prosentase cacat yang seragam.

Tabel 5

Data Prosentase Cacat

\begin{tabular}{|c|l|c|}
\hline No & \multicolumn{1}{|c|}{$\begin{array}{c}\text { Kode } \\
\text { Produk }\end{array}$} & $\begin{array}{c}\text { Prosentase Cacat } \\
(\%)\end{array}$ \\
\hline 1 & CT $60 \mathrm{ml}$ & 0.5 \\
\hline 2 & CT $120 \mathrm{ml}$ & 0.5 \\
\hline 3 & L-BS $100 \mathrm{ml}$ & 0.5 \\
\hline 4 & L-BS $300 \mathrm{ml}$ & 0.5 \\
\hline
\end{tabular}

\section{Alternatif Produksi}

Pada PT. Berlina Plastics Pandaan menggunakan beberapa macam alternatif produksi demi terpenuhinya semua permintaan yang sekali waktu bisa melonjak di departement pembotolan, seperti kapasitas dan biaya tenaga kerja dapat dilihat pada tabel dibawah ini:

Tabel 6

Data Alternatif Produksi

\begin{tabular}{|c|l|c|c|}
\hline No & \multicolumn{1}{|c|}{$\begin{array}{c}\text { Alternatif } \\
\text { Produksi }\end{array}$} & $\begin{array}{c}\text { Kapasitas } \\
\text { (jam/Org/Hr) }\end{array}$ & $\begin{array}{c}\text { Biaya } \\
\text { (rupiah) }\end{array}$ \\
\hline 1 & Reguler Time & 16 & $14000 / \mathrm{jam} / \mathrm{kru}$ \\
\hline 2 & Over Time & 3 & $25000 / \mathrm{jam} / \mathrm{kru}$ \\
\hline 3 & Inventory & - & - \\
\hline 4 & Subkontrak & - & - \\
\hline
\end{tabular}

Sumber: P.T. Berlina Plastics (Juni

2002)

\section{HASIL DAN PEMBAHASAN}

\section{Peramalan permintaan}

Untuk meramalkan permintaan di sini digunakan sofware OS, dan dicoba untuk beberapa metode,dan hasil perhitungan MAPE serta peramalan untuk 6 periose mendatang adalah sebagai berukut : 


\section{Tabel 6}

Metode Terpilih Dengan MAPE Terkecil

\begin{tabular}{|c|l|l|c|}
\hline No & Kode Produk & Metode Peramalan Terpilih & MAPE \\
\hline 1 & CT $60 \mathrm{ml}$ & Moving Average & $4 \%$ \\
\hline 2 & CT $120 \mathrm{ml}$ & Double Exponential Smoothing & $9 \%$ \\
\hline 3 & L-BS $100 \mathrm{ml}$ & Double Exponential Smoothing & $5 \%$ \\
\hline 4 & L-BS $300 \mathrm{ml}$ & Double Exponential Smoothing & $3 \%$ \\
\hline
\end{tabular}

Dengan berbagai metode peramalan yang memiliki MAPE terkecil, maka didapat ramalan permintaan sebagai berikut:

Tabel 7

Ramalan Permintaan 6 Periode Mendatang

\begin{tabular}{|c|l|c|c|c|c|}
\hline No & \multicolumn{1}{|c|}{ Periode } & $\begin{array}{c}\text { CT 60 } \\
\text { ml }\end{array}$ & $\begin{array}{c}\text { CT 1 20 } \\
\text { ml }\end{array}$ & $\begin{array}{c}\text { L-BS 100 } \\
\text { mI }\end{array}$ & $\begin{array}{c}\text { L-BS 300 } \\
\text { ml }\end{array}$ \\
\hline 1 & Juli 2002 & 472574 & 233573 & 419598 & 360269 \\
\hline 2 & Agustus 2002 & 472574 & 234534 & 427598 & 367308 \\
\hline 3 & September 2002 & 472574 & 235494 & 435598 & 374346 \\
\hline 4 & Oktober 2002 & 472574 & 236455 & 443598 & 381384 \\
\hline 5 & November 2002 & 472574 & 237416 & 451599 & 388423 \\
\hline 6 & Desember 2002 & 472574 & 238376 & 459599 & 395461 \\
\hline
\end{tabular}

\section{Perencanaan Produksi (Production Planning)}

Perencanaan produksi merupakan jadwal produksi bulanan untuk masingmasing produk. Perencanaan produksi akan dibuat dalam periode 6 bulan. Dalam pembuatan rencana produksi ini, dilakukan dengan pendekatan metode linear programming, yang telah dikembangkan oleh Bedworth. Pada sub-sub bab berikut ini disajikan perhitungan-perhitungan yang dipakai dalam pengembangan model linear.

\section{Permintaan Produksi}

Hasil peramalan yang yang diperoleh merupakan perkiraan permintaan produk (baik) pada masa yang akan datang. Akan tetapi pada proses pembuatan produk biasanya terdapat reject (cacat), sehingga perlua adanya penyesuaian terhadap besarnya reject. Dengan demikian permintaan produksi harus mempertimbangkan prosentase cacat produksi sebagai penyesuaian dengan rumus:

$$
\mathrm{P}_{\mathrm{gij}, \mathrm{t}}=\frac{P_{o i j, t}}{1-P_{i j}}
$$

\section{Keterangan :}

$\mathrm{P}_{\mathrm{gij}, \mathrm{t}}=$ Jumlah yang harus diproduksi (ij) pada periode $t$

$\mathrm{P}_{\text {oij, } \mathrm{t}}=$ Hasil ramalan permintaan produk $\mathrm{j}$ dalam produk 1 pada periode $t$

$\mathrm{P}_{\mathrm{ij}} \quad=$ Prosentase cacat untuk produk $\mathrm{j}$ dalam group I

$\mathrm{P}_{\mathrm{gij}, \mathrm{t}}=\frac{472574}{1-0.1}=525082.22 \approx 525082$ unit

Untuk selanjutnya permintaan yang sudah disesuaikan dengan prosentase cacat ini digunakan sebagai nilai permintaan 
yang harus dipenuhi oleh perusahaan untuk 6 periode mencatang, terhitung mulai Juli 2002 sampai dengan Desember 2002 dan nilai-nilai tersebut dapat dilihat pada tabel berikut dengan menggunakan perhitungan manual yang sama seperti diatas :

Tabel 8

Demand Sesuai Dengan Prosentase Cacat

\begin{tabular}{|c|l|c|c|c|c|}
\hline \multirow{2}{*}{ No } & \multicolumn{1}{|c|}{ Periode } & \multicolumn{4}{|c|}{ Produksi (unit) } \\
\cline { 3 - 6 } & & $\begin{array}{c}\text { CT 60 } \\
\text { mI }\end{array}$ & CT 120 ml & $\begin{array}{c}\text { L-BS 100 } \\
\text { ml }\end{array}$ & $\begin{array}{c}\text { L-BS 300 } \\
\text { ml }\end{array}$ \\
\hline 1 & Juli 2002 & 525082 & 259526 & 466220 & 400299 \\
\hline 2 & Agustus 2002 & 525082 & 260593 & 475109 & 408120 \\
\hline 3 & September 2002 & 525082 & 261660 & 483998 & 415940 \\
\hline 4 & Oktober 2002 & 525082 & 262728 & 492887 & 423760 \\
\hline 5 & November 2002 & 525082 & 263796 & 501777 & 431581 \\
\hline 6 & Desember 2002 & 525082 & 264862 & 510666 & 439401 \\
\hline
\end{tabular}

\section{Kapasitas Produk Reguler}

Kapasitas produksi reguler merupakan out put per hari (sudah termasuk allowance) yang dikalikan jumlah hari kerja dalam periode tersebut. Dengan perhitungan secara manual :

$$
170000 \text { (unit) } \times 27 \text { (hari) }=459000 \text { (unit) }
$$

Dengan perhitungan yang sama didapatkan hasil :

Tabel 9

Kapasitas Produk Reguler

\begin{tabular}{|c|c|c|c|c|c|}
\hline \multirow{2}{*}{ No } & Periode & \multicolumn{4}{|c|}{ Produksi Reguler } \\
\cline { 3 - 6 } & & $\begin{array}{c}\text { CT 60 ml } \\
\text { (unit) }\end{array}$ & $\begin{array}{c}\text { CT 120 } \\
\text { ml } \\
\text { (unit) }\end{array}$ & $\begin{array}{c}\text { L-BS 100 } \\
\text { ml } \\
\text { (unit) }\end{array}$ & $\begin{array}{c}\text { L-BS 300 } \\
\text { mI } \\
\text { (unit) }\end{array}$ \\
\hline 1 & Juli 2002 & 459000 & 405000 & 432000 & 351000 \\
\hline 2 & Agustus 2002 & 442000 & 390000 & 416000 & 338000 \\
\hline 3 & September 2002 & 425000 & 375000 & 400000 & 325000 \\
\hline 4 & Oktober 2002 & 442000 & 390000 & 416000 & 338000 \\
\hline 5 & November 2002 & 442000 & 390000 & 416000 & 338000 \\
\hline 6 & Desember 2002 & 391000 & 345000 & 368000 & 299000 \\
\hline
\end{tabular}

\section{Kapasitas Produk Overtime}

Merupakan kapasitas produksi over time per hari (sudah termasuk allowance) yang dikalikan dengan jumlah hari dalam periode tersebut. Dengan perhitungan :

$$
\begin{aligned}
& 3187 \text { (unit) x } 27 \text { (hari) } \\
& =86049 \text { (unit) }
\end{aligned}
$$

Nilai dibawah ini merupakan kapasitas out put per hari untuk overtime dengan menggunakan perhitungan yang sama pula dengan diatas. 
Tabel 9

Kapasitas Produksi Overtime

\begin{tabular}{|c|l|c|c|c|c|}
\hline No & \multicolumn{1}{|c|}{ Periode } & $\begin{array}{c}\text { CT 60 } \\
\text { mI } \\
\text { (unit) }\end{array}$ & $\begin{array}{c}\text { CT 120 } \\
\text { ml } \\
\text { (unit) }\end{array}$ & $\begin{array}{c}\text { L-BS 100 } \\
\text { ml } \\
\text { (unit) }\end{array}$ & $\begin{array}{c}\text { L-BS 300 } \\
\text { ml } \\
\text { (unit) }\end{array}$ \\
\hline I & Juli 2002 & 86049 & 75924 & 81000 & 65799 \\
\hline 2 & Agustus 2002 & 82862 & 73112 & 78000 & 63362 \\
\hline 3 & September 2002 & 79675 & 70300 & 75000 & 60925 \\
\hline 4 & Oktober 2002 & 82862 & 73112 & 78000 & 63362 \\
\hline 5 & November 2002 & 82862 & 73112 & 78000 & 63362 \\
\hline 6 & Desember 2002 & 73301 & 64676 & 69000 & 56051 \\
\hline
\end{tabular}

\section{Persediaan Awal Produk}

Sisa produk pada akhir bulan Juni 2002 merupakan stock awal produk untuk bulan Juli 2002, seperti yang tercatat pada tabel 4.7. Stock masing-masing produk yang terdapat pada akhir Juni 2002 bukan merupakan ketetapan nilai inventori, jadi bisa berubah setiap saat dan bisa jadi tidak ada inventori pada suatu periode.

\section{Biaya Produksi}

Biaya produksi disini antara lain merupakan biaya pemakaian listrik, pemakaian bahan baku dan lain-lain selain biaya reguler time dan over time

Tabel 10

\section{Biaya Produksi}

\begin{tabular}{|c|l|c|c|}
\hline No & Kode Produk & $\begin{array}{c}\text { Unit Cost } \\
\text { (Rp/unit) }\end{array}$ & $\begin{array}{c}\text { Inventory } \\
\text { (Rp/unit) }\end{array}$ \\
\hline 1 & CT $60 \mathrm{ml}$ & 150 & 7.5 \\
\hline 2 & CT $120 \mathrm{ml}$ & 200 & 10 \\
\hline 3 & L-BS $100 \mathrm{ml}$ & 175 & 8.75 \\
\hline 4 & L-BS 300 ml & 280 & 14 \\
\hline
\end{tabular}

\section{Biaya Subkontrak}

Untuk mengatasi lonjakan dari permintaan yang tidak dapat dipenuhi baik dari reguler time, over time, maupun inventori maka kebijakan perusahaan adalah subkontrak pada perusahaan lain dengan harga sesuai dengan kebijakan perusahaan yang bersangkutan dan nilainya tertera dibawah ini.

Tabel 11

Biaya Sub Kontrak

\begin{tabular}{|c|l|c|}
\hline No & Kode Produk & $\begin{array}{c}\text { Subkontrak } \\
\text { (Rp/unit) }\end{array}$ \\
\hline 1 & CT $60 \mathrm{ml}$ & 300 \\
\hline 2 & CT $120 \mathrm{ml}$ & 400 \\
\hline 3 & L-BS $100 \mathrm{ml}$ & 350 \\
\hline 4 & L-BS $300 \mathrm{ml}$ & 500 \\
\hline
\end{tabular}

Pengembangan Model

Dalam pembuatan model matematis, dasar acuan yang dipakai adalah model matematis menurut Bedworth (1986) dan dari hasil pemodelan dapat dibedakan menjadi tiga bagian yaitu:

1. Variabel Keputusan

2. Fungsi Tujuan dan koefisien fungsi tujuan

3. Fungsi Pembatas / Constrains dan koefisien fungsi pembatas.

Variabel - variabel keputusan dalam model perencanaan produksi ini adalah :

$>\mathrm{P}_{\mathrm{ij}}$ : Jumlah produk $\mathrm{i}$ yang diproduksi pada bulan ke j ( unit ).

$>\mathrm{I}_{\mathrm{ij}}$ : Jumlah persediaan produk $\mathrm{i}$ pada akhir bulan ke j ( unit ). 
$>\mathrm{S}_{\mathrm{ij}}$ : Jumlah subkontrsk produk $\mathrm{i}$ pada bulan ke j ( unit ).

$>\mathrm{R}_{\mathrm{j}}$ : Jumlah jam reguler yang tersedia pada periode $\mathrm{j}$.

$>\mathrm{O}_{\mathrm{j}}$ : Jumlah jam lembur yang tersedia pada periode $\mathbf{j}$.

$>\mathrm{U}_{\mathrm{j}}$ : Jumlah under time pada periode $\mathrm{j}$.

$\mathrm{i}=$ Jenis produk $(\mathrm{i}=1,2,3,4)$.

$\mathrm{j}=$ Periode perencanaan $(\mathrm{j}=$

$$
1,2,3,4,5,6) \text {. }
$$

\section{Fungsi Tujuan}

Formulasi bentuk fungsi Objective dari Linier Programming untuk minimasi total cost adalah :

$\operatorname{Min} \mathrm{Z}=\sum_{t=1}^{T} \mathrm{~A}_{\mathrm{p}, \mathrm{t}} \mathrm{P}_{\mathrm{t}}+\mathrm{A}_{\mathrm{r}, \mathrm{t}} \mathrm{R}_{\mathrm{t}}+\mathrm{A}_{\mathrm{o}, \mathrm{t}} \mathrm{O}_{\mathrm{t}}+$

$$
A_{i, t} I_{t}+A_{s, t} S_{t}+A_{c, t} C_{t}+A_{t, t} L_{t}
$$

\section{Dengan Constrain :}

2. Mendapatkan rencana produksi berupa Jadwal Induk Produksi sbb. :

\begin{tabular}{|l|c|c|c|c|c|c|}
\hline \multirow{2}{*}{ Produk } & \multicolumn{5}{|c|}{ Periode } \\
\cline { 2 - 7 } & $\begin{array}{c}\text { Juli } \\
\mathbf{2 0 0 2}\end{array}$ & $\begin{array}{c}\text { Agustus } \\
\mathbf{2 0 0 2}\end{array}$ & $\begin{array}{c}\text { September } \\
\mathbf{2 0 0 2}\end{array}$ & $\begin{array}{c}\text { Oktober } \\
\mathbf{2 0 0 2}\end{array}$ & $\begin{array}{c}\text { November } \\
\mathbf{2 0 0 2}\end{array}$ & $\begin{array}{c}\text { Desember } \\
\mathbf{2 0 0 2}\end{array}$ \\
\hline CT $60 \mathrm{ml}$ & 607463 & 434116 & 515667 & 525082 & 610304 & 439860 \\
\hline CT $120 \mathrm{ml}$ & 236726 & 260593 & 261660 & 262728 & 263796 & 264862 \\
\hline L-BS $100 \mathrm{ml}$ & 448220 & 475109 & 483998 & 492887 & 501777 & 510666 \\
\hline L-BS $300 \mathrm{ml}$ & 370299 & 408120 & 415940 & 423760 & 431581 & 439401 \\
\hline
\end{tabular}

3. Biaya yang dikeluarkan oleh perusahaan untuk memproduksi semua jenis produk mulai bulan Juli 2002 sampai dengan bulan Desember 2002 sebesar Rp 214480268,00

\section{DAFTAR PUSTAKA}

Baker, Kenneth R., Sequensing Rules and Due Date Assigment in A Job Shop, Manajement Sceince, Vol. 30 n0. 9.

Dervitsiotis, Kostas N., Operation

Management, Mc., Graw Hill, Inc., 1994.

$$
\begin{array}{lr}
I_{t}-S_{t}=I_{t-1}+S_{t-1}+P_{t}-F_{t} & t=1,2, . . T \\
R_{t}=R_{t-1}+C_{t}-L_{t} & t=1,2, . T T \\
O_{t}-U_{t}=k_{1} P_{t}-R_{t} & t=1,2, . . T \\
P_{t}, R_{t}, O_{t}, I_{t}, S_{t}, C_{t}, L_{t}, U_{t}, \geq 0 & \\
& t=1,2, . . T
\end{array}
$$

\section{KESIMPULAN}

1. Mendapatkan total jumlah over time, under time maupun inventori yang sedikit seperti pada tabel 5.3, sehingga tidak ada pembengkakan untuk biaya over time dan under time dengan pengalokasian berbagai aktifitas yang seimbang 
Bethworth, David D. and Bailey, James E., 1982, Integrate Production Control

System, New york, John Wiley and Sons Inc.

Gerald Keller, Brian Warrack, 2000, Statistics For Management And economics, Fifth Edition, Duxbury Thomson Learning,

Lincolin Arsyad, 1994 , Peramalan Bisnis, Edisi I, BPFE Yogyakarta.
Richard Bronson, Hans J. Waspakrik, 1991, Teori Dan Soal-Soal Operasional Research, Seri Buku Schaum's, Erlangga,.

Subagyo Pangestu, 1991., T. Hani Handoko, Marwan Asri, Dasar-dasar Operation Research, Edisi II, BPFE, Yogyakarta. 